\title{
DEVELOPMENT OF NANOEMULSION TO IMPROVE THE OCULAR BIOAVAILABILITY AND PATIENT COMPLIANCE IN POSTOPERATIVE TREATMENT USING INDOMETHACIN
}

\section{DIVYA AJMEERA ${ }^{1}$, SARANGAPANI MANDA ${ }^{2}$, KRISHNAVENI JANAPAREDDI ${ }^{3}$, SUSMITHA KOLLURI ${ }^{4}$}

\author{
1-4University College of Pharmaceutical Sciences, Kakatiya University, Warangal, India 506009
}

Email: divyaphdku@gmail.com

Received: 07 Mar 2020, Revised and Accepted: 03 Apr 2020

\section{ABSTRACT}

Objective: To develop a new cationic nanoemulsion (NE) for ophthalmic delivery of indomethacin (IND) to improve the permeability and retention time of formulations, thereby improving the drug's ocular bioavailability.

Methods: Based on the solubility profile of indomethacin in various solvents, captex 8000 was selected as oil phase, span 20 as a surfactant and tween 20 as co-surfactant to construct pseudo ternary phase diagrams and nanoemulsion region was recognized. Sonication was used as the method of NE preparation. Optimization was done using $3^{2}$ factorial designs by considering the oil and the ratio of surfactant to co-surfactant (Smix) quantities as independent variables and evaluated for different physicochemical properties. Ex vivo transcorneal permeability was studied using bovine cornea, the In vivo drug pharmacokinetics of optimized NE and marketed formulation were assessed in rabbit aqueous humor and also in plasma.

Results: The mean globule size, zeta potential, viscosity, refractive index, $\mathrm{pH}$, surface tension and the osmolarity values for the prepared indomethacin nanoemulsions (IND-NEs) were found between $129.8 \pm 1.1$ to $191.4 \pm 1.6 \mathrm{~nm},+13.20 \pm 4.6$ to $+23.45 \pm 4.82,15.3 \pm 0.1$ to $32.7 \pm 0.0 \mathrm{mPas}$, $1.346 \pm 0.007$ to $1.386 \pm 0.005,5.5 \pm 0.4$ to $6.9 \pm 0.9,32.0 \pm 2.6$ to $52.3 \pm 3.4 \mathrm{mN} / \mathrm{m}$ and $303-395 \mathrm{mOsm} / \mathrm{l}$ respectively and all these values found to be falling under the recommended values for ophthalmic use. From the In vitro release studies, it was found that the IND-NEs exhibited sustained drug release with $67.91 \pm 2.01$ to $95.90 \pm 1.93 \%$ drug release at 24 h when compared to the drug solution which showed $99.81 \pm 5.21 \%$ drug release within $2 \mathrm{~h}$. The Ex vivo drug permeation through the corneal membrane at $4 \mathrm{~h}$ from the optimized $\mathrm{NE}$ and drug solution was found to be $524 \pm 1.5 \mu \mathrm{g} / \mathrm{cm}^{2}$ and $175 \pm 2.6 \mu \mathrm{g} / \mathrm{cm}^{2}$ respectively. Further, the optimized NE was found to be nonirritant with the lowest ocular irritation potential (Iirr) of 1 towards the rabbit's eyes. The area under the drug concentration vs. time curve for $24 \mathrm{~h}\left(\mathrm{AUC}_{(0-24 \mathrm{~h})}\right)$ for optimized NE and the marketed formulation was found to be $1514.99 \mathrm{ng} / \mathrm{ml} / \mathrm{h}$ and $974.14 \mathrm{ng} / \mathrm{ml} / \mathrm{h}$ in aqueous humour; $2266.83 \mathrm{ng} / \mathrm{ml} / \mathrm{h}$ and $778.15 \mathrm{ng} / \mathrm{ml} / \mathrm{h}$ in $\mathrm{plasma} \mathrm{respectively.}$

Conclusion: Due to its improved corneal absorption and prolonged drug release along with less systemic absorption, the optimized NE offers an effective postoperative treatment with increased ocular bioavailability and improved patient compliance with a decrease in the number of installations per day and a decrease or disappearance of systemic side effects of IND.

Keywords: Cationic nanoemulsion, Ophthalmic drug delivery, Permeability, Bioavailability, Optimization, Indomethacin $3^{2}$ factorial designs, Sonication, Captex 8000, Aqueous humor, Ocular irritation

(C) 2020 The Authors. Published by Innovare Academic Sciences Pvt Ltd. This is an open access article under the CC BY license (http://creativecommons.org/licenses/by/4.0/) DOI: http://dx.doi.org/10.22159/ijap.2020v12i3.37371. Journal homepage: https://innovareacademics.in/journals/index.php/ijap

\section{INTRODUCTION}

Postoperative pain and irritation symptoms are relatively common during the first hours after surgery [1], which is associated with a breakdown of the blood-aqueous barrier as a result of surgical trauma induced prostaglandin production. In general, corticosteroids are prescribed to control postoperative inflammation; however, they found increasing intraocular pressure, delaying in corneal epithelial and stromal wound healing, and more susceptible to microbial infections. Hence, the use of non-steroidal anti-inflammatory drugs becomes an alternative treatment [2].

The topical route is preferred to administer ophthalmic dosage forms due to benefits like the ease of application, targetability, reduced side effects and also cost-effectiveness [3]. Most of the conventional ophthalmic dosage forms are in an aqueous solution of water-soluble drugs and either as an ointment or suspension of water-insoluble drugs. Frequent administration is required for aqueous solutions due to poor ocular bioavailability and drug loss through the nasolacrimal drainage which may lead to extremely unwanted pharmacokinetics and systemic toxicity suggesting the necessity of new alternatives to ocular drug delivery. Coming to the water-insoluble drugs, ointments suffer from poor patient acceptance because of blurred vision and matted eyelids, and suspensions lead to particle irritation, poor bioavailability, and changes in polymorphism and particle size upon storage [4] Besides, the complex structure of the human eye can limit the bioavailability of ocular drugs. Due to poor ocular bioavailability, higher concentrations of the conventional form of analgesic used during surgery may result in ocular and systemic side effects.
NEs are advantageous for topical ocular drug delivery due to their ability to solubilize drugs in a large quantity, enhance absorption, achieve sustained drug release and target the affected area of the eye [5]. NEs are kinetically stable colloidal dispersions with droplet sizes on the order of $100 \mathrm{~nm}$. Because of their small size, they are optically transparent in appearance, possess high surface area per unit volume, have excellent stability and variable viscosity [6]. Apart from their excellent physicochemical properties and stability, the NE systems for ocular delivery are easy to fabricate and characterize. NEs can deliver both hydrophilic and lipophilic drug moieties both to the anterior and posterior segments of the eye, in a safe and reproducible manner with improved patient compliance [7]. Because of the increased bioavailability and reduced drug toxicity, the NEs may serve as the potential delivery systems for ocular administration [8].

The objective of the present study was to develop a new cationic NE for ophthalmic delivery of indomethacin IND with improved permeability and retention time thereby improving drug's ocular bioavailability.

\section{MATERIALS AND METHODS}

\section{Materials}

IND was received as a gift sample from Sreeji Pharma International, Vadodara, India. The materials like captex 100, captex 200, captex 355, captex 8000, were generously donated by Abitec Corporation, Mumbai, India. Capryol 90, capmul MCM C8, capmul MCM L8, labrafil M 1994, labrafil M 2125 and acconon E were gifted from Gettefosse, Saint-Priest Cedex, France. Tween 20, tween 40, tween 80, polyethyleneglycol (PEG) 200, propylene glycol (PG), span 20 were purchased from Himedia Laboratories, Mumbai, India. Water was double-distilled and used 
throughout the study. High-performance liquid chromatography (HPLC) grade solvents (methanol and acetonitrile) were used for drug analysis. All other chemicals used in the present study were of analytical reagent grade and were purchased from S D Fine Chemicals, India. The In vivo studies were conducted in healthy adult New Zealand albino rabbits free from visible ocular abnormalities, weighing about 2-3 $\mathrm{kg}$ of either sex and were procured from Jeeva Life Sciences, Hyderabad. The study protocol (IAEC/49/UCPSc/KU/2018) was approved by the institutional animal ethical committee, University College of Pharmaceutical Sciences, Kakatiya University, Warangal, Telangana, India.

\section{Quantitative analysis of IND}

\section{Stock solution and working sample preparation}

$100 \mathrm{mg}$ of IND was dissolved in $50 \mathrm{ml}$ of HPLC grade methanol and the final volume was adjusted up to $100 \mathrm{ml}$ to prepare a stock solution of $1000 \mu \mathrm{g} / \mathrm{ml}$ concentration. For the calibration curve, the stock solution was again diluted with the help of diluents to get final working concentrations of $10-500 \mathrm{ng} / \mathrm{ml}$.

\section{Quantitative analysis conditions}

The quantitative analysis of IND was performed using ultrafast liquid chromatography (UFLC, Shimadzu L220) containing LC-20AD isocratic pump, SPD-20A UV/Vis detector, and rheodyne injector was used. The UFLC process was carried out on a C8 column (100 $\mathrm{mm} \times 4.6 \mathrm{~mm}$ and the particle size of $5 \mu \mathrm{m}$ ). The mobile phase comprised of $0.5 \% \mathrm{v} / \mathrm{v}$ 0-Phosphoric acid: methanol: acetonitrile in the ratio of 40:20:40, respectively. The flow rate was set at 1.0 $\mathrm{ml} / \mathrm{min}$ and about $20 \mu \mathrm{l}$ of sample solutions were injected into the UFLC in triplicate using Hamilton microsyringe and measured at a wavelength of $270 \mathrm{~nm}$ [9].

The chromatographic data analysis was done by using the LC solution software. A standard plot of concentration of the drug (ng/ml) vs. peak area was plotted. The linearity of the calibration curve was established by the correlation coefficient value obtained from the graph.

\section{Solubility study}

The solubility of IND in quite a few solvents was determined by adding an excess amount of drug in $2 \mathrm{ml}$ of the solvent (captex 100, captex 200, captex 355, captex 8000, capryol 90, capmul MCM C8, capmul MCM L8, labrafil M 1994, labrafil M 2125, acconol E, tween 20, tween 40, tween 80, PEG 200, PG and span 20) individually in $5 \mathrm{ml}$ stopper vials and mixed with a vortex mixer for $10 \mathrm{~min}$. To attain an equilibrium, the vials were stored at $25{ }^{\circ} \mathrm{C}$ in an isothermal shaker for $72 \mathrm{~h}$. The samples were centrifuged at $3000 \mathrm{rpm}$ for $30 \mathrm{~min}$. The supernatant was collected and filtered using a $0.22 \mathrm{~mm}$ membrane filter. The concentration of IND in the filtrate was analyzed by the UFLC [10].

\section{Ternary phase diagrams}

The most stable emulsion systems usually consist of blends of two or more emulsifiers, one portion having lipophilic tendencies, the other hydrophilic [11]. To find out the suitable blend that can better solubilize IND and can form emulsions of nano-size, the aqueous titration method was used to make pseudo ternary systems and the pseudo ternary diagrams were plotted using CHEMIX School software [12]. Surfactant and co-surfactants were mixed in altered weight proportions of 1:1,1:2,1:3and 2:1 and were designated as Smix ratios. Then, altered weight ratios of oil and Smix (1:9, 2:8, 3:7, $4: 6,5: 5,6: 4,7: 3,8: 2$ and 9:1) were prepared $[13,14]$ and the aqueous phase was added dropwise to each altered weight ratios of oil and Smix with continuous stirring till solution converts turbid. For every phase diagram, the systems were inspected for the transparency in appearance visually.

\section{Optimization by $3^{2}$ factorial designs}

A 2-factor, 3-level factorial design using Design-Expert (Version 12, Stat-Ease Inc., Minneapolis, MN) software was applied to optimize the formulation compositions. The selected independent variables and experimental responses were the percentage of oil (X1) and Smix (X2); and mean globule size (Y1) and percentage drug release (Y2), respectively. Table 1 illustrates the selected factor levels from the phase diagram for the factorial design. To recognize the significant effect of independent variables on the experimental responses, response surface analyses were carried out [15].

\section{Preparation of IND-NEs}

IND-NEs were prepared by the ultrasonic emulsification method by using probe sonicator. A total of 9 NEs were prepared in which the oil phase contained drug, oil and Smix, and aqueous phase contained PG dissolved in water. IND $(0.1 \% \mathrm{w} / \mathrm{v})$ was added by vortexing into the optimized quantity of oil and Smix until clear solutions were obtained. The hot aqueous phase $\left(50^{\circ} \mathrm{C}\right)$ was dropwise added to the oil phase with continuous stirring at $250 \mathrm{rpm}$ using a magnetic stirrer to produce a primary emulsion, which is then sonicated at an amplitude of 50, pulse $5 \mathrm{~s}$ on and $3 \mathrm{~s}$ off for $10 \mathrm{~min}$ to get nanoemulsion [16].

\section{Physicochemical evaluation of IND-NEs}

\section{Particle size measurements}

The mean globule size of the IND-NEs was determined by using photon correlation spectroscopy (Zeta seizer, ZS Nano, Malvern Instruments Ltd., UK), which analyzes the fluctuations in the light scattering of the particle. Light scattering was checked at $25^{\circ} \mathrm{C}$ at a $90^{\circ}$ angle. While zeta potential measurements were performed using a disposable zeta cuvette. For each sample, the mean diameter and zeta potential \pm standard deviation of three determinations was calculated applying multimodal analysis [17].

\section{Viscosity determination}

The viscosity of the IND-NEs was determined using Brookfield viscometer (Model DV-II+Pro Brookfield Ltd, Middleboro, MA) using a C $50-1$ spindle at $25 \pm 0.5^{\circ} \mathrm{C}$ in triplicate $[18,19]$.

\section{Refractive index and pH measurement}

The refractive index of the IND-NEs was measured by using an Abbes refractometer by placing one drop of formulation on the slide (Nirmal International, New Delhi, India) at $25 \pm 0.5^{\circ} \mathrm{C}$ in triplicate. The $\mathrm{pH}$ of the NEs was measured by a digital $\mathrm{pH}$ meter (DPH 504) in triplicate at $25^{\circ} \mathrm{C}[20]$.

\section{Surface tension measurements}

Surface tension measurements were carried out by the Du Nouy ring method using an electronic Tensiometer (model-K100, KRÜSS, Germany) [21]. The force referred to the wetted length acting on a ring as a result of the tension of the withdrawn liquid lamella when moving the ring from one phase to another is measured in this method and the mathematical formula involved is as followed.

$$
\sigma=F / l \cdot \cos \theta \text {---------- (1) }
$$

\section{Osmolarity determination}

Osmolarity is an important parameter by which one can predict the irritability of the formulation. It was calculated using the following equation [22].

Milli osmoles per liter $=\frac{\text { Mass in grams }}{\text { Molecular wt }\left(\frac{\mathrm{g}}{\mathrm{ml}}\right)} *$ particle number $* 1000-$

\section{Stability testing}

To evaluate the stability, IND-NEs were subjected to thermodynamic stability testing, which comprises of a heating-cooling cycle, freezethaw cycle and centrifugation. The nanoemulsions were examined for stability at temperatures $45{ }^{\circ} \mathrm{C}$ (heating) and $4{ }^{\circ} \mathrm{C}$ (cooling) subsequently for not less than $48 \mathrm{~h}$. These alternating cycles of heating and cooling were repeated at least six times. Selected nanoemulsions were kept in a deep freezer at $-20{ }^{\circ} \mathrm{C}$ for about $48 \mathrm{~h}$. After that, the nanoemulsions were removed from the freezer and kept at room temperature $\left(25^{\circ} \mathrm{C}\right)$ to return to the original form. This step of freeze-thaw was repeated 2-3 times. After freeze-thaw cycle nanoemulsions were subjected to centrifugation where they were centrifuged at $3,500 \mathrm{rpm}$ for $30 \mathrm{~min}$, and checked for any phase separation, change in mean globule size and drug content [23].

\section{Drug content}

A small fixed volume of IND-NEs was taken and diluted with methanol. Then the samples were analyzed by using UFLC and the concentrations were calculated from the calibration curve $[24,25]$. 


\section{In vitro release study}

In vitro release of IND-NEs was evaluated and compared with that of control by the diffusion technique using Franz diffusion cells and dialysis membrane. $1 \mathrm{ml}$ of simulated tear fluid (STF) with a dose equivalent amount of IND was served as control. The setup was kept under continuous stirring with a Teflon-coated magnetic bar on a magnetic stirrer at $100 \mathrm{rpm}$, maintaining a constant temperature of $32 \pm 0.5{ }^{\circ} \mathrm{C} .1 \mathrm{ml}$ sample was withdrawn at every predetermined time points i.e. $0.5,1,2,4,6,8,12$ and $24 \mathrm{~h}$. The same amount of fresh STF was replaced into the receiver compartment. Withdrawn samples were estimated for the drug content by UFLC $270 \mathrm{~nm}$ [26].

\section{Surface morphology}

Transmission electron microscopy (TEM) was used to study the morphology of the optimized $\mathrm{NE}$ observed under different magnifications by following the standard protocol practicing at RUSKA Labs, PV Narshimha Rao Telangana Veterinary University, Telangana, India. For the TEM study, a drop of the NE was appropriately diluted with water and applied on a carbon-coated grid, and then treated with a drop of $2 \%$ phosphotungstic acid and kept aside for the 30s. The carbon-coated grid was then dried and taken onto a slide and observed under the microscope. A combination of bright field imaging at cumulative magnification and diffraction modes was used to evaluate the size and morphology of the NE [27].

\section{Ex vivo corneal permeation studies}

The Ex vivo permeation studies were carried out using bovine corneas, which is a reliable method for the prediction of drug transport across the corneal membrane. The eyeballs of bovine were obtained from a slaughterhouse and transported to the laboratory in normal saline maintained at $4{ }^{\circ} \mathrm{C}$. The corneas were carefully removed along with a 5-6 mm of surrounding sclera and washed with cold saline. The washed corneas were kept in cold, freshly prepared STF of $\mathrm{pH}$ 7.4. The study was carried out by using Franz-diffusion cells in such a way that the epidermal side was in intimate contact with the formulation in the donor compartment. The receptor compartment was filled with STF at $34 \pm 0.5{ }^{\circ} \mathrm{C}$. The receptor medium was stirred at $50 \mathrm{rpm}$. The samples were withdrawn at different time intervals and replaced with an equal volume of STF. The permeation study was carried out for $4 \mathrm{~h}$, and samples were analyzed by UFLC at $270 \mathrm{~nm}$. Results were expressed as the mean of three experiments \pm SD. The amount of drug permeated per unit area through the excised cornea $(\mu \mathrm{g} / \mathrm{cm} 2)$ versus time $(\mathrm{h})$ was plotted and the permeation parameters of drug in the different formulae were calculated [28-30].

\section{In vivo studies}

\section{Ocular irritation studies}

Ocular irritancy of optimized NE was studied on healthy adult New Zealand albino rabbits free from visible ocular abnormalities, weighing about $2-3 \mathrm{~kg}$ of either sex. $30 \mu \mathrm{l}$ of test formulation previously sterilized using $0.2 \mu \mathrm{m}$ syringe filter was instilled into the right eye of each rabbit $(\mathrm{n}=3)$ and observed for ocular irritation reactions like redness, conjunctival chemosis and discharge for $24 \mathrm{~h}$ keeping the untreated eye as a control. The scoring was given from 0 to 4 for the absence to highest observed abnormality and an on the whole Iirr was calculated by summing up the total scores for each category. The Iirr of more than 4 was considered the presence of clinically significant irritation [31].

\section{Drug pharmacokinetics in plasma}

6 Rabbits were divided into 2 groups of three animals each. Gruop1 received control (Indocollyre $0.1 \%$ ophthalmic solution, Bosch and Lomb) and Group 2 received test (optimized NE) samples of $30 \mu \mathrm{l}$ each. $200 \mu \mathrm{l}$ of blood samples were collected into heparinized tubes at $0.5,0.75,1,2,4,8,12$ and $24 \mathrm{~h}$ time-points through the marginal vein. After collection, samples were immediately stored at temperature $\left(-20^{\circ} \mathrm{C}\right)$ until the analysis $[32,33]$.

\section{Drug pharmacokinetics in aqueous humour}

To study and compare the pharmacokinetics of optimized NE in aqueous humour with that of marketed formulation, 24 animals (three animals corresponding to each sampling point) were used and the time points include 0.5, 0.75, 1, 2, 4, 8, 12 and 24h. Each animal was placed in an individual restraining box, $30 \mu \mathrm{l}$ of the test sample (optimized NE) and control (marketed product) were topically applied on to the right eye and left eye, respectively. $100 \mu \mathrm{l}$ of aqueous humor was collected from three animals at each time point by inserting $22 \mathrm{G}$ needle of an insulin syringe into the anterior segment of the eye through the cornea without causing any injury to iris and lens. Before collecting the samples, a combination of 35 $\mathrm{mg} / \mathrm{kg}$ ketamine hydrochloride and $5 \mathrm{mg} / \mathrm{kg}$ xylazine was used to anesthetize the rabbits by injecting intramuscularly [34]. After collection, samples were immediately stored at temperature $\left(-20^{\circ} \mathrm{C}\right)$ until the analysis.

\section{Analysis of aqueous humour and blood samples}

Different calibration standards ranging from $50-500 \mathrm{ng} / \mathrm{ml}$ were prepared by adding $10 \mu \mathrm{l}$ of known working solution of drug to $90 \mu \mathrm{l}$ of drug-free rabbit aqueous humor/blood. All samples were vortexed to ensure complete mixing and $20 \mu \mathrm{l}$ was used for UFLC analysis. The aqueous humor/blood samples collected were mixed with $200 \mu \mathrm{l}$ of acetonitrile, vortexed and centrifuged for $30 \mathrm{~min}$ at $3000 \mathrm{rpm} .20 \mu \mathrm{l}$ of the organic phase was used for UFLC analysis [35, 36].

\section{RESULTS AND DISCUSSION}

\section{Calibration curve}

The calibration curve was plotted between peak area and concentration $(\mathrm{ng} / \mathrm{ml})$ as shown in fig. 1 . The linearity was seen at a concentration range of 2.5 to $100 \mathrm{ng} / \mathrm{ml}$ with a regression coefficient $\left(R^{2}\right)$ value of 0.998 . The retention time was found to be $5.4 \pm 0.34 \mathrm{~min}$ as shown in fig. 2.

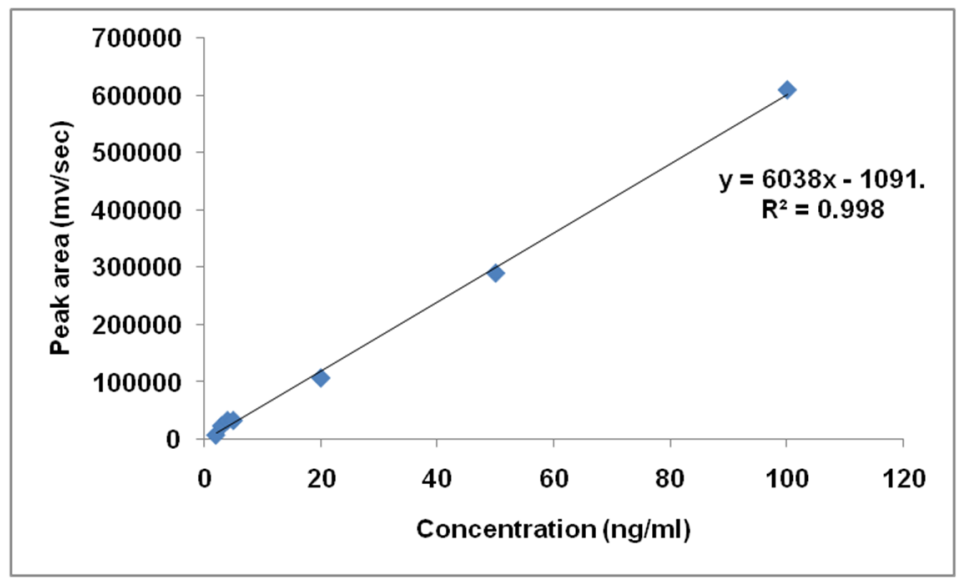

Fig. 1: Calibration curve 


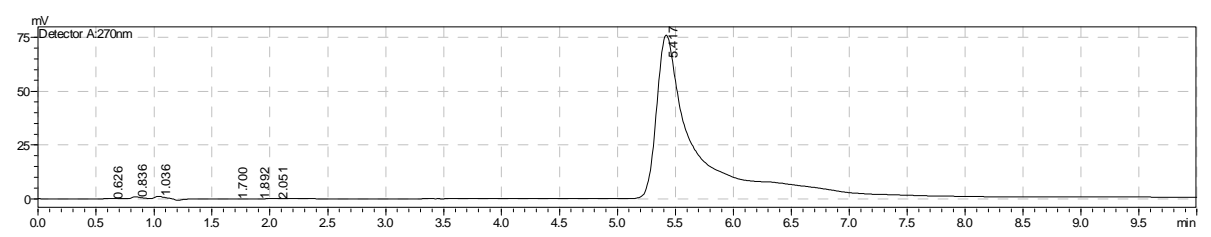

Fig. 2: UFLC chromatogram of IND (RT-5.4)

\section{Solubility study}

The solubility of IND in various oils, surfactants and co-surfactants were depicted in fig. 3. Among oils, captex 8000 showed very good solubility. Therefore, it was selected as the oil phase. Among surfactants and co-surfactants, IND had the highest solubility in span 20 and tween 20; hence they were selected as surfactant and cosurfactant respectively for the phase study.

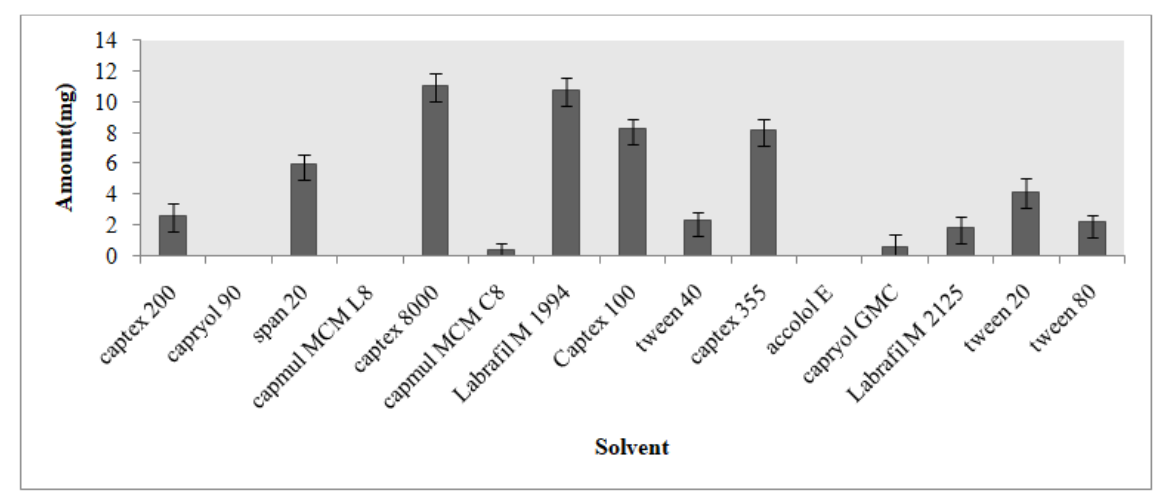

Fig. 3: Indomethacin solubility in various solvents, *error bars represent standard deviations of three replicates

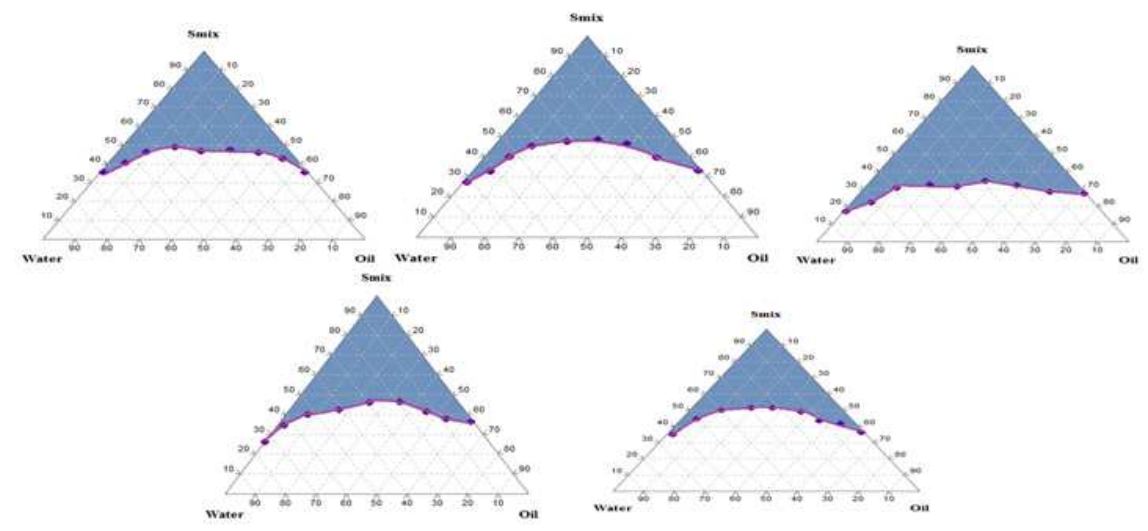

Fig. 4: Ternary phase diagrams for Smix ratios $(1: 1,1: 2,1: 3,2: 1$ and 3:1 from right to left)

Table 1: $3^{2}$ factorial design showing independent and dependent variables

\begin{tabular}{|c|c|c|c|c|}
\hline \multirow[t]{2}{*}{ Formulation code } & \multicolumn{3}{|c|}{ Coded value } & Actual value \\
\hline & X1 & $\mathrm{X} 2$ & X1 & $\mathrm{X} 2$ \\
\hline IND-NE1 & 1 & 1 & 15 & 60 \\
\hline IND-NE2 & -1 & 0 & 12.5 & 55 \\
\hline IND-NE3 & -1 & 1 & 12.5 & 60 \\
\hline IND-NE4 & 1 & 0 & 15 & 55 \\
\hline IND-NE5 & 0 & -1 & 10 & 50 \\
\hline IND-NE6 & -1 & -1 & 12.5 & 50 \\
\hline IND-NE7 & 0 & 1 & 10 & 60 \\
\hline IND-NE8 & 0 & 0 & 10 & 55 \\
\hline IND-NE9 & 1 & -1 & 15 & 50 \\
\hline \multirow[t]{2}{*}{ Independent variables } & \multicolumn{4}{|l|}{ Levels } \\
\hline & \multicolumn{2}{|l|}{ Low $(-1)$} & Medium (0) & High (1) \\
\hline X1-amount of oil (\%w/w) & \multicolumn{2}{|l|}{10} & 12.5 & 15 \\
\hline $\mathrm{X} 2$-amount of Smix $(\% \mathrm{w} / \mathrm{w})$ & \multicolumn{2}{|c|}{50} & 55 & 60 \\
\hline \multirow[t]{2}{*}{ Dependent variables } & \multicolumn{4}{|c|}{ Y1-Mean droplet size (nm) } \\
\hline & \multicolumn{4}{|c|}{ Y2-Cumulative drug release $(\%)$} \\
\hline
\end{tabular}


Table 2: Formulation composition

\begin{tabular}{|c|c|c|c|c|}
\hline Formulation code & Oil (\%w/v) & Surfactant mix (\% w/v) & 1\% Propylene glycol (\%w/v) & Aqueous phase (\%v/v) \\
\hline IND-NE1 & 15 & 60 & 2.5 & 22.5 \\
\hline IND-NE2 & 10 & 55 & 2.5 & 32.5 \\
\hline IND-NE3 & 10 & 60 & 2.5 & 27.5 \\
\hline IND-NE4 & 15 & 55 & 2.5 & 27.5 \\
\hline IND-NE5 & 12.5 & 50 & 2.5 & 35 \\
\hline IND-NE6 & 10 & 50 & 2.5 & 37.5 \\
\hline IND-NE7 & 12.5 & 60 & 2.5 & 25 \\
\hline IND-NE8 & 12.5 & 55 & 2.5 & 30 \\
\hline IND-NE9 & 15 & 50 & 2.5 & 32.5 \\
\hline
\end{tabular}

*IND and cetalkonium chloride content remained constant at $0.1 \% \mathrm{w} / \mathrm{v}$ and $0.01 \% \mathrm{w} / \mathrm{v}$ respectively in all formulations

\section{Physicochemical evaluation}

The IND-NEs found suitable for ocular delivery with satisfactory physicochemical characteristics and the complete profile was depicted in table 3 . The mean globule size for all of the IND-NEs was found less than $200 \mathrm{~nm}$ ranging from $129.8 \pm 1.1$ to $191.4 \pm 1.6 \mathrm{~nm}$ confirming the successful formation of NE. This small size could be related to the penetration of the co-surfactant molecules into the surfactant film. This would decrease the fluidity and surface viscosity of the interfacial film, lower the radius of curvature of the droplets and thus form transparent systems [37]. The zeta potential of IND-NEs ranged from $+13.20 \pm 4.6$ to $+23.45 \pm 4.82$. The positive charge helps to improve the retention time and also helps in improving corneal absorption due to electrostatic interactions with the corneal membrane [38]. The viscosity ranged from $15.3 \pm 0.1$ to $32.7 \pm 0.0$ mPas. In general, $15-150 \mathrm{mPas}$ of viscosity is recommended as this low viscosity will ensure the transparency and hence no visual impairment upon eye drop instillation into the eyes without compromising the prolonged retention time [39]. Refractive index measurements tell about the possibility of discomfort to the patient after the administration of eye drops. It is recommended that eye drops should have refractive index values near to that of tear fluid i.e., 1.340 to 1.360 or not higher than 1.476 and for the prepared IND-NEs, the refractive index values ranged from $1.346 \pm 0.007$ to $1.386 \pm 0.005$ which are within the recommended value. The ideal $\mathrm{pH}$ for maximum comfort to the eye is of $7.2 \pm 0.2$. However, the human eye can tolerate a $\mathrm{pH}$ of 3.5 to 8.5 . The $\mathrm{pH}$ values of the IND-NEs were found in the range of $5.5 \pm 0.4$ to $6.9 \pm 0.9$ and hence provide better comfort to the eyes [40]. The surface tension of the IND-NEs was found to be in the range of $32.0 \pm 2.6$ to $52.3 \pm 3.4 \mathrm{mN} / \mathrm{m}$ ensuring the good spreadability of the IND-NEs over the corneal membrane. The osmolarity values of IND-NEs were found within the range of 303-395 mOsm/l falling under the recommended values [41].

\section{Stability}

IND-NEs remained clear with no phase separation or drug precipitation, indicating their excellent physical stability. All the formulations were found to be consistent concerning their mean globule size, drug content, phase separation and transparency during the stability study. The physical data comparing their mean globule size and drug content before and after stability studies were given in table 4.

\section{In vitro release studies}

To facilitate comparison between release behaviors of different NE formulae, the In vitro drug release profiles of the IND-NEs were graphically illustrated in fig. 5. The release results of NE revealed that the prepared formulations were found to exhibit sustained release with $67.91 \pm 2.01$ to $95.90 \pm 1.93 \%$ drug release at $24 \mathrm{~h}$ in comparison to control which showed 99.81 $\pm 5.21 \%$ drug release within $2 \mathrm{~h}$. The variation in drug release between IND-NEs can be emphasized from the formulation composition variables and the droplet size of the formulations.

Table 3: Physical data of different evaluation parameters

\begin{tabular}{|c|c|c|c|c|c|c|c|c|}
\hline Formulation code & MGS (nm) & PDI & $\mathrm{ZP}(\mathrm{mV})$ & $\begin{array}{l}\text { Viscosity } \\
\text { (mPas) }\end{array}$ & pH & RI & $\begin{array}{l}\text { Surface tension } \\
(\mathrm{mN} / \mathrm{m})\end{array}$ & $\begin{array}{l}\text { Osmolarity } \\
(\mathrm{mOsm} / \mathrm{l})\end{array}$ \\
\hline IND-NE1 & $152.8 \pm 1.9$ & $0.070 \pm 0.000$ & $+14.1 \pm 5.25$ & $15.3 \pm 0.1$ & $6.9 \pm 0.9$ & $1.346 \pm 0.007$ & $52.3 \pm 3.4$ & 382 \\
\hline IND-NE2 & $183.8 \pm 1.1$ & $0.209 \pm 0.110$ & $+17.8 \pm 5.86$ & $16.8 \pm 0.1$ & $6.7 \pm 0.2$ & $1.347 \pm 0.002$ & $49.5 \pm 2.5$ & 337 \\
\hline IND-NE3 & $180.1 \pm 0.8$ & $0.253 \pm 0.012$ & $+15.3 \pm 4.83$ & $20.7 \pm 0.2$ & $6.8 \pm 0.6$ & $1.368 \pm 0.002$ & $46.4 \pm 3.7$ & 324 \\
\hline IND-NE4 & $157.7 \pm 1.5$ & $0.031 \pm 0.021$ & $+14.7 \pm 3.51$ & $18.4 \pm 0.1$ & $6.9 \pm 0.5$ & $1.348 \pm 0.005$ & $44.1 \pm 1.9$ & 352 \\
\hline IND-NE5 & $137.3 \pm 1.6$ & $0.272 \pm 0.040$ & $+22 \pm 4.09$ & $22.3 \pm 0.5$ & $6.8 \pm 0.7$ & $1.346 \pm 0.001$ & $41.5 \pm 1.8$ & 368 \\
\hline IND-NE6 & $191.4 \pm 1.6$ & $0.512 \pm 0.001$ & $+13.2 \pm 4.6$ & $24.4 \pm 0.2$ & $5.9 \pm 0.6$ & $1.369 \pm 0.001$ & $43.1 \pm 4.0$ & 372 \\
\hline IND-NE7 & $116.4 \pm 1.5$ & $0.318 \pm 0.003$ & $+22.6 \pm 5.45$ & $20.1 \pm 0.0$ & $6.8 \pm 0.3$ & $1.340 \pm 0.001$ & $39 \pm 2.5$ & 379 \\
\hline IND-NE8 & $128.9 \pm 1.1$ & $0.237 \pm 0.011$ & $+23 \pm 4.82$ & $26.0 \pm 0.1$ & $5.5 \pm 0.4$ & $1.368 \pm 0.002$ & $32 \pm 2.6$ & 381 \\
\hline IND-NE9 & $176.5 \pm 2.0$ & $0.318 \pm 0.005$ & $+18.4 \pm 3.84$ & $32.7 \pm 0.0$ & $6.9 \pm 0.8$ & $1.386 \pm 0.005$ & $37.9 \pm 3.5$ & 355 \\
\hline
\end{tabular}

*Values are expressed as mean \pm SD $(n=3)$, MGS-mean globule size, PDI-poly dispersity index, ZP-zeta potential, RI-refractive index.

Table 4: Physical evaluation data of before and after stability studies

\begin{tabular}{llll}
\hline Formulation code & \multicolumn{2}{c}{ Mean globule size (nm) } & Drug content (\%) \\
\cline { 2 - 4 } & Freshly prepared & After stability studies & Freshly prepared \\
\hline NF1 & $152.8 \pm 1.9$ & $150.12 \pm 0.44$ & $99.52 \pm 0.12$ \\
NF2 & $183.8 \pm 1.1$ & $185.42 \pm 0.13$ & $96.51 \pm 1.06$ \\
NF3 & $180.1 \pm 0.8$ & $182.71 \pm 0.42$ & $97.35 \pm 1.83$ \\
NF4 & $157.7 \pm 1.5$ & $159.14 \pm 0.56$ & $95.72 \pm 1.27$ \\
NF5 & $137.3 \pm 1.6$ & $138.18 \pm 0.54$ & $99.47 \pm 0.54$ \\
NF6 & $191.4 \pm 1.6$ & $194.62 \pm 0.34$ & $98.34 \pm 1.05$ \\
NF7 & $116.4 \pm 1.5$ & $118.24 \pm 0.55$ & $96.96 \pm 1.99$ \\
NF8 & $128.9 \pm 1.1$ & $129.13 \pm 0.81$ & $98.92 \pm 1.92$ \\
NF9 & $176.5 \pm 2.0$ & $179.02 \pm 0.65$ & 98.42 \\
\hline
\end{tabular}

*Values are expressed as mean \pm SD $(n=3)$ 


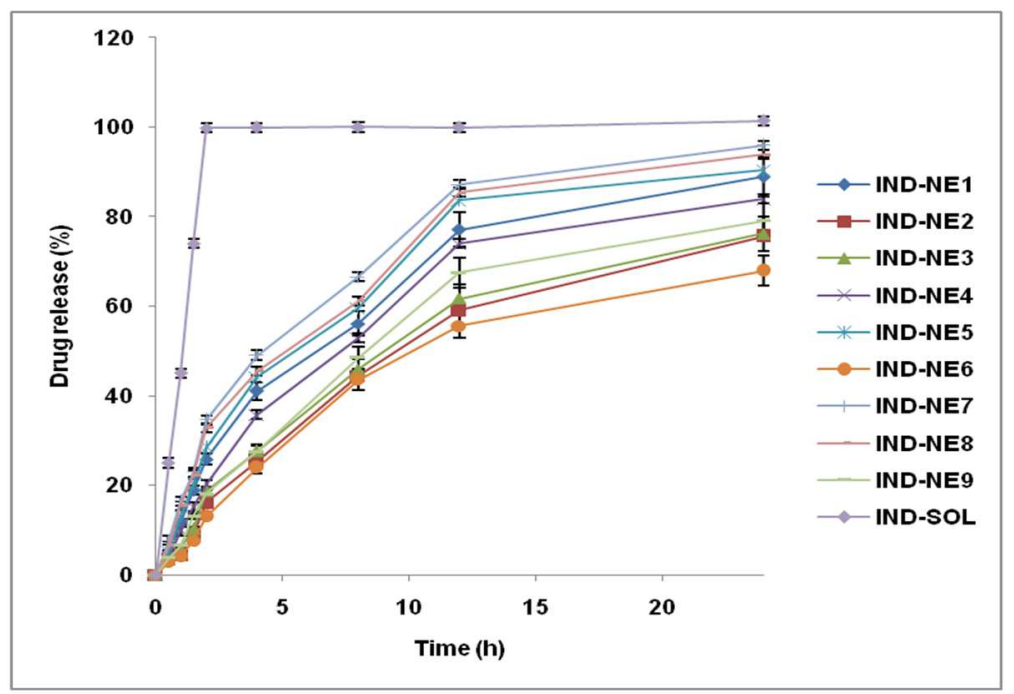

Fig. 5: In vitro drug release profiles, *error bars represent standard deviations of three replicates

\section{Optimization by response surface analysis}

The experimental data were fitted into the quadratic model and the predicted $\mathrm{R}^{2}$ of mean globule size and \% drug release were found to be 0.9505 and 0.8177 respectively and were in reasonable agreement with the adjusted $\mathrm{R}^{2}$ of 0.9852 and 0.9599 respectively; i.e. the difference is less than 0.2. Adequate precision measures the signal to noise ratio. A ratio greater than 4 is desirable. Here, the ratio of 27.662 for mean globule size and 17.793 for \% drug release indicated an adequate signal. The model found significant with the Fvalue of 107.49 for mean globule size and 39.33 for \% drug release. $\mathrm{P}$-values less than 0.0500 indicate that the model terms are significant. The model terms $\mathrm{A}, \mathrm{B}, \mathrm{AB}, \mathrm{A}^{2}, \mathrm{~B}^{2}$ were found significant for both mean globule size and $\%$ drug release.

The final equation in terms of coded factors for mean globule size $\left(\mathrm{Y}_{1}\right)$ and $\%$ drug release $\left(\mathrm{Y}_{2}\right)$ :

$Y_{1}=125.811-11.2833 X_{1}-9.28333 X_{2}-3.15 X_{1} X_{2+} 46.0833 X_{1}^{2}+2.58333 X_{2}{ }^{2}--(3)$

$Y_{2}=94.1444+5.37167 X 1+3.81167 X 2+0.36$ X1X2-14.4817 X1 2-1.56167 X2 2 $---(4)$

From the response surface analysis, it was evident that the oil and Smix compositions showed a significant effect on mean globule size and \% drug release. The effects were represented as 3D surface plots in fig. 6. It is prominently noticed that an increase in oil content provided a decrease in globule size to some extent and a further increase in oil content lead to a slight increase in globule size and an opposite effect was seen for percentage drug release. However, by increasing the Smix content, the globule size decreased and the percentage drug release increased. Zainol S et al. (2012) reported an increase in the mean globule size when the oil composition of levodopa lipid emulsions was increased [42]. Reddy et al. (2011) developed felodipine nanoemulsions and reported that the mean globule size reduced from 231.8 to $162.7 \mathrm{~nm}$ by increasing the surfactant concentration from 1 to $1.5 \%$ [43]. In the present study, the drug release was found to be affected by their droplet size. The decrease in droplet size increased the total number of oil globules and a subsequent increase in their surface area, which led to an increase in drug release. Thus the formulation IND-NE7 with the medium oil and high Smix was found to have the lowest mean globule size and significantly high drug release; hence it was chosen as the optimized formulation and was subjected to further study. Similar results were reported by Yadav et al. (2020) where low oil and high surfactant levels of emulsion composition for ezetimibe showed the lowest globule size of $24.4 \pm 2.07 \mathrm{~nm}$ and high \% drug release [44]. (a)

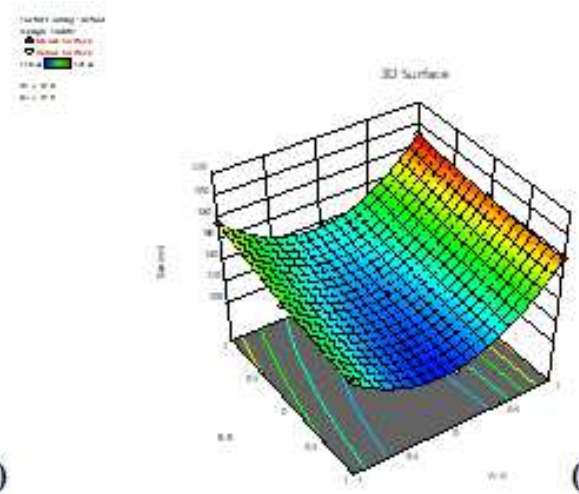

(b)
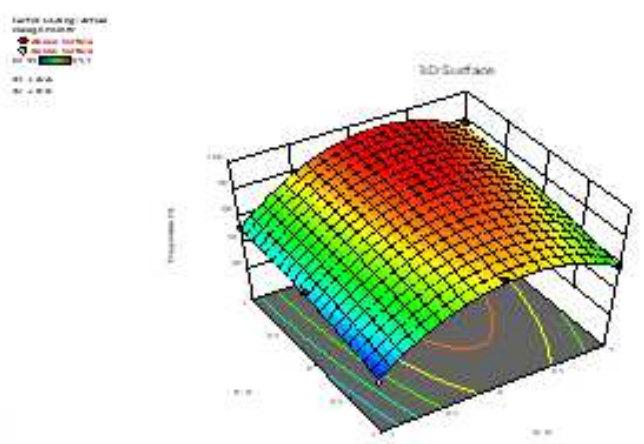

Fig. 6: 3D Response surface plots showing the effect of oil and Smix content on (a) mean globule size (nm), (b) Drug release (\%)

\section{Surface morphology}

The droplets in the IND-NE7 appeared dark, and spherical with size more or less similar and less than $100 \mathrm{~nm}$. The image can be seen in fig. 7.

\section{Ex vivo corneal permeation studies using bovine corneas}

The drug permeated through the corneal membrane at $4 \mathrm{~h}$ from the IND-NE7 and drug solution was found to be $524 \pm 1.5 \mu \mathrm{g} / \mathrm{cm}^{2}$ and $175 \pm 2.6 \mu \mathrm{g} / \mathrm{cm}^{2}$, respectively. The results for the drug solution 
were found quite the opposite to the in vitro drug diffusion rate. This can be explained by the structural complexity of the corneal membrane that opposes the aqueous solution because of the outer lipophilic layer. In the case of IND-NE7, the nano-sized globules can be easily infiltrated by endocytosis and the permeation enhancing the ability of the formulation ingredients will cause temporary changes in the tight junctions of the corneal membrane that enhances the permeation by transcellular pathway. Similar results were reported by Sayed et al. (2017), where the high in vitro drug diffusion rate from the drug solution was reversed in case of corneal permeation and the nanovesicles showed more corneal permeation compared to the drug solution due to the above said reasons [45]. The graphical representation of the comparative ex vivo drug permeation profiles of test and control were shown in fig. 8 and the drug permeation parameters were depicted in table 5 .

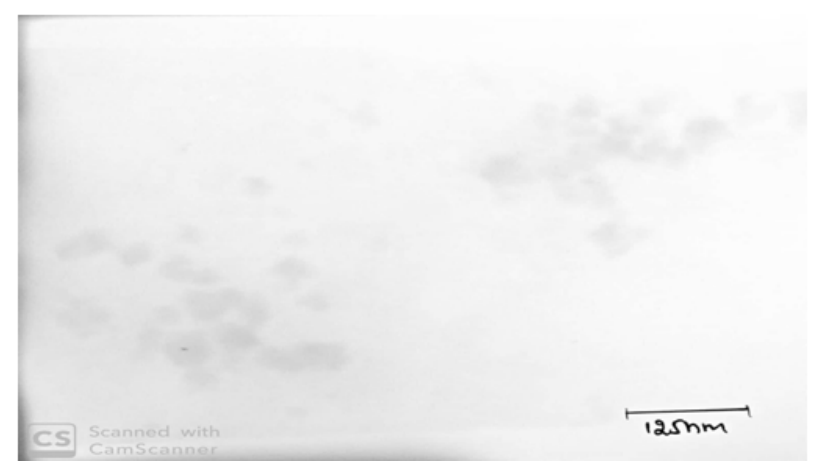

Fig. 7: TEM image of optimized formulation (IND-NE7)

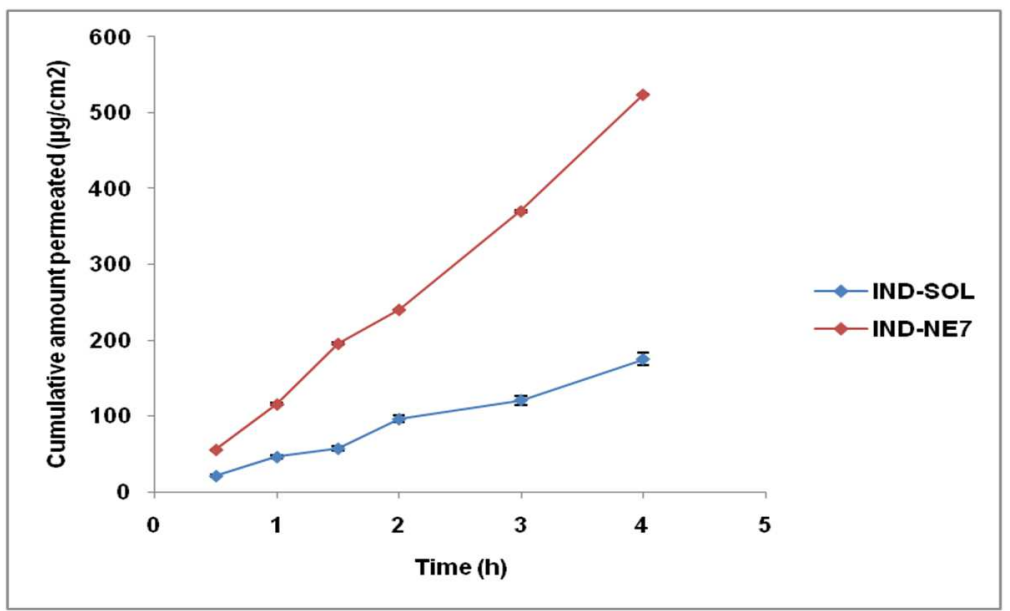

Fig. 8: Ex vivo drug permeation profiles, *error bars represent standard deviations of three replicates

Table 5: Ex vivo drug permeation parameters

\begin{tabular}{lll}
\hline Parameter & Control & Test formulation \\
\hline Flux $\left(\mu \mathrm{g} / \mathrm{cm}^{2} / \mathrm{h}\right)$ & 55.732 & 166.878 \\
Papp $(\mathrm{cm} / \mathrm{s})$ & $1.54 \times 10^{-5}$ & $4.63 \times 10^{-5}$ \\
Corneal hydration $(\%)$ & $72.2 \pm 0.13$ & $66.5 \pm 0.24$ \\
\hline
\end{tabular}

*Values are expressed as mean \pm SD $(n=3)$

\section{Ocular irritation test}

IND-NE7 found nonirritant with a minimal score of 1 in the Draize eye test. The rabbits showed slight redness of the conjunctiva, which disappeared completely within $15 \mathrm{~min}$, but no lachrymation or chemosis was observed throughout the study indicating the optimized formulation is nonirritant and could be tolerated by the rabbit eye.

\section{In vivo pharmacokinetics}

The graphical representation of the comparative In vivo drug concentration profiles of test and control was shown in fig. 9 and the pharmacokinetic parameters were depicted in table 6 . The $\mathrm{AUC}_{(0-24 \mathrm{~h})}$ for IND-NE7 and the marketed formulation was found to be 1514.99 $\mathrm{ng} / \mathrm{ml} / \mathrm{h}$ and $974.14 \mathrm{ng} / \mathrm{ml} / \mathrm{h}$ in aqueous humour; $2266.83 \mathrm{ng} / \mathrm{ml} / \mathrm{h}$ and $778.15 \mathrm{ng} / \mathrm{ml} / \mathrm{h}$ in plasma respectively. The plasma levels and aqueous humor levels of IND confirmed that 1.55 fold increased bioavailability in the aqueous humour and 2.91 fold decreased bioavailability in the systemic circulation of IND-NE7 when compared to the marketed IND ophthalmic solution. The reason for improved corneal absorption can be explained by the small globule size, improved retention time due to viscosity and the positive charge on the droplets imparted by cetalkonium chloride involved in the electrostatic interaction with the negatively charged corneal membrane and that lead to improved residence time on cornea [46]. Ban J et al. (2017) reported similar results for dexamethasone lipid nanoparticles, which showed a 2.7 fold increased bioavailability in aqueous humour compared to the drug solution due to the nano-size and positive charge on the nanoparticles [47]. 


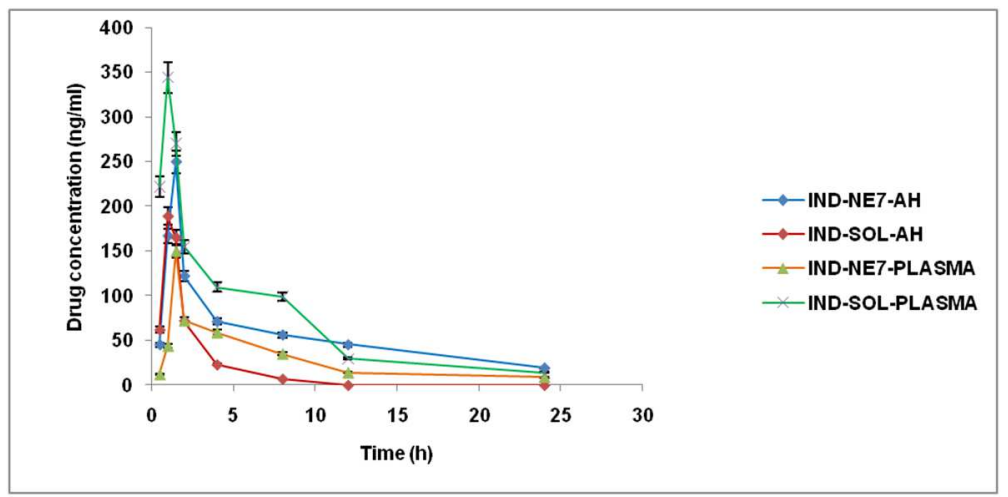

Fig. 9: In vivo drug concentration profile, *error bars represent standard deviations of three replicates

Table 6: Pharmacokinetic parameters in the rabbit model

\begin{tabular}{|c|c|c|c|c|}
\hline \multirow[t]{2}{*}{ Parameter } & \multicolumn{2}{|c|}{ Aqueous humor } & \multicolumn{2}{|l|}{ Plasma } \\
\hline & Control & Test formulation & Control & Test formulation \\
\hline $\operatorname{AUC}_{(0-24 \mathrm{~h})}(\mathrm{ng} / \mathrm{ml} / \mathrm{h})$ & 974.14 & 1514.99 & 2266.83 & 778.15 \\
\hline $\operatorname{Tmax}(\mathrm{h})$ & 1 & 1.5 & 1 & 1.5 \\
\hline Cmax (ng/ml) & 189.15 & 250.45 & 270.22 & 150.73 \\
\hline
\end{tabular}

*Values are expressed as mean \pm SD $(n=3)$

Table 7: One sample t-test for IND-NE7 vs. control formulation

\begin{tabular}{lll}
\hline One sample t-test & INDO-NE7 & Plasma \\
\cline { 2 - 3 } & Aqueous humour & 155.5 \\
\hline Actual mean & 57.56 & 8 \\
Number of values & 8 & $\mathrm{t}=3.793, \mathrm{df}=7$ \\
$\mathrm{t}, \mathrm{df}$ & $\mathrm{t}=2.362, \mathrm{df}=8$ & 0.0068 \\
P value & 0.0458 & Yes \\
Significant (alpha=<0.05) & Yes & 58.57 to 252.4 \\
$95 \%$ confidence interval & 1.373 to 113.7 & 0.6727 \\
$\mathrm{R}^{2}$ & 0.4109 & \\
\hline
\end{tabular}

The obtained results were found to be statistically significant when analyzed by a one-sample t-test using GraphPad Prism software version, 8.0.2 and were depicted in table 7.

\section{CONCLUSION}

Novel cationic IND-NEs for topical ophthalmic delivery were prepared successfully using captex 8000 , span 20 , tween 20, PG and glycerol. Almost all prepared IND-NEs showed acceptable physicochemical properties and thermodynamic stability. However, IND-NE7 showed the highest drug release among all and was nonirritant to the rabbits' eyes. The drug release rate from NEs was found to be dependent on the oil and Smix content used in NE preparation. IND-NE7 improved IND permeation across the bovine cornea and showed improved corneal absorption with prolonged drug release compared to marketed eye drops. Thus, IND-NE7 offers an effective postoperative treatment with increased ocular bioavailability and improved patient compliance with a decrease in the number of installations per day and a decrease or disappearance of systemic side effects of IND.

\section{ACKNOWLEDGMENT}

The authors would like to acknowledge the financial support by the University Grants Commission, New Delhi, India in the form of NFST (National Fellowship for the Higher Education of ST Students).

\section{FUNDING}

Nil

\section{AUTHORS CONTRIBUTIONS}

All the authors have contributed equally.

\section{CONFLICT OF INTERESTS}

None to declare

\section{REFERENCES}

1. Susanna PT, Kai K, Merja K, Sinikka P, Hannu K. A prospective study on postoperative pain after cataract surgery. Clin Ophthalmol 2013;7:1429-35.

2. Ahuja M, Dhake AS, Sharma SK, Majumdar DK. Topical ocular delivery of NSAIDs. AAPS J 2008;10:229-41.

3. Patel A, Cholkar K, Agrahari V, Mitra AK. Ocular drug delivery systems: an overview. World J Pharmacol 2013;2:47-64.

4. Shulin D. Recent developments in ophthalmic drug delivery. Pharm Sci Technol Today 1998;1:325-38.

5. Pranita S, Amrita B. Nanoemulsions-a review. Int J Res Pharm Chem 2016;6:312-22.

6. Ankur GA, Burak EH, Alan HT, Patrick DS. Nanoemulsions: formation, properties and applications. Soft Matter 2016;12:116.

7. Hegde RR, Verma A, Ghosh A. Microemulsion: New Insights into the ocular drug delivery. ISRN Pharm 2013;2013:1-11.

8. Li G, Jing W, Min J, Hanah B, Ouyang D, Frank E, et al. Recent advances in topical ophthalmic drug delivery with lipid-based nanocarriers. Drug Discovery Today 2013;18:290-7.

9. Boyka T, Ivanka P, Alexander Z, Plamen P. Performance liquid chromatographic assay of indomethacin and its related substances in tablet dosage forms. Int J Pharm Pharm Sci 2012;4:549-52.

10. Adnan A, Rizwan M, Farhan JA, Zeenat I, Roop KK, Aqil M, et al. Nanoemulsion components screening and selection: a technical note. AAPS PharmSciTech 2009;10:69-76. 
11. Cristhian Yarce. The HLB system: a timesaving guide to emulsifier selection. Wilmington [DE]: ICI Americas Inc; 1992.

12. Parasuram RR, Guruprasad S. Nanoemulsion based emulgel formulation of lipophilic drug for topical delivery. Int J Pharmtech Res 2016;9:210-23.

13. Georgeta C, Vicenţiu V, Ioana O, Ana MM, Dan FA, Cornelia I, et al. Development and evaluation of new micro emulsion-based hydrogel formulations for topical delivery of fluconazole. AAPS PharmSciTech 2015;16:889-904.

14. Muza MR, Taha UW, Neeraj M, Hasham SS, Roqia A, Faheem SA. Development and characterization of drug-loaded selfsolidnano-emulsified drug delivery system for treatment of diabetes. Mater Sci Res India 2018;15:1-11.

15. Patel N, Nakrani H, Raval M, Sheth N. Development of loteprednol etabonate-loaded cationic nano emulsified in-situ ophthalmic gel for sustained delivery and enhanced ocular bioavailability. Drug Delivery 2016;23:3712-23.

16. Sneha P, Marina K, Suchetha Kumari N. Nanoemulsion components screening of quetiapine fumarate: effect of surfactant and co-surfactant. Asian J Pharm Clin Res 2015;8:136-40.

17. Shah J, Nair AB, Jacob S, Patel RK, Shah H, Shehata TM, et al. Nanoemulsion based vehicle for effective ocular delivery of moxifloxacin using experimental design and pharmacokinetic study in rabbits. Pharmaceutics 2019;11:230-46.

18. Chikte AA, Umekar MJ, Borkhade MN, Raut NS. Effect of transesterification of oil on nanoemulsion gel for topical drug delivery. Int J Pharm Sci Res 2018;9:589-98.

19. Ali MS, Alam MS, Alam N, Siddiqui MR. Preparation, characterization and stability study of dutasteride loaded nanoemulsion for treatment of benign prostatic hypertrophy. Iran J Pharm Res 2014;13:1125-40.

20. Syafinaz Z, Mahiran B, Emilia AM. Formulation optimization of a palm-based nanoemulsion system containing levodopa. Int J Mol Sci 2012;13:13049-64.

21. Pratap SB, Brajesh K, Jain SK, Shafaat K. Development and characterization of a nanoemulsion gel formulation for transdermal delivery of carvedilol. Int J Drug Dev Res 2012;4:151-61.

22. Florence AT, Attwood D. Physicochemical properties of drugs in solution: physicochemical principles of pharmacy. 4th ed. Pharmaceutical Press; 2006. p. 69-73.

23. Harwansh RK, Patra KC, Pareta SK, Singh J, Rahman MA. Nanoemulsions as vehicles for transdermal delivery of glycyrrhizin. Braz J Pharm Sci 2011;47:769-78.

24. Mowafaq GM, Abulfadhel NJ. Formulation and characterization of nimodipine nanoemulsion as ampoule for oral route. Int J Pharm Sci Res 2017;8:591-602.

25. Khalid N, Gaofeng S, Brenden HJ, Kobayashid I, Mitsutoshi N, Colin Barrowa J. Formulation and characterization of $\mathrm{O} / \mathrm{W}$ nanoemulsions encapsulating high concentration of astaxanthin. Food Res Int 2017;102:364-71.

26. Usha GK, Sree HN, Balakeshwa R, Prakash RB, Subramanian R. Enhanced trans-corneal permeability of valacyclovir by polymethacrylic acid copolymers based ocular microspheres: in vivo evaluation of estimated pharmacokinetic/ pharmacodynamic indices and simulation of aqueous humor drug concentration-time profile. J Pharm Innov 2016;11:82-91.

27. Laxman M. Electron microscopy as a tool in research and disease diagnosis. Lead paper compendium published and presented in IAVP annual conference XXXI, held at Anand, Gujarat, India; 2014. p. 139-60.

28. Agarwal $\mathrm{P}$, Rupenthal ID. In vitro and ex vivo corneal penetration and absorption models. Drug Delivery Transl Res 2016;6:634-47.
29. Maria SM, Maria ACP, Vicent R, Cristina BF, Alicia LC. Ex vivo rabbit cornea diffusion studies with a soluble insert of moxifloxacin. Drug Delivery Transl Res 2018;8:132-9.

30. Peter WJM, Natalia NP, Sukhmanpreet C, Lgiz AS, Charlene L, Irina IS, et al. Crown ethers: novel permeability enhancers for ocular drug delivery. Mol Pharm 2017;14;3528-38.

31. Lou J, Hu W, Tian R, Zhang H, Jia Y, Zhang J, et al. Optimization and evaluation of a thermoresponsive ophthalmic in situ gel containing curcumin-loaded albumin nanoparticles. Int J Nanomed 2014;9:2517-25.

32. Marongiu ML, Gulinati A, Floris B. A procedure for rabbit blood serial collection. Ital J Anim Sci 2007;6:773-9.

33. Parasuraman S, Raveendran R, Kesavan R. Blood sample collection in small laboratory animals. I Pharmacol Pharmacother 2010;1:87-93.

34. Rajendra SK, Gajanan J, Miller O, Uday BK. Ocular pharmacokinetics of dorzolamide and brinzolamide after single and multiple topical dosing: implications for effects on ocular blood flow. Drug Metab Dispos 2011;39:1529-37.

35. Sonia HT, Ehab EF, Rawda SM. Simultaneous determination of timolol maleate in combination with some other anti-glaucoma drugs in rabbit aqueous humor by high-performance liquid chromatography-tandem mass spectroscopy. J Chromatogr B 2016;1022:109-17

36. Shital PS, Rajesh PK, Abhishek JB, Ahmed AA, Jamaan A, Shital BB. Anti-inflammatory and antioxidative stress effects of oryzanol in glaucomatous rabbits. J Ophthalmol 2017;2017:1-9.

37. Lucia P, Diego RP, Giulia B, Marco C, Giovanni FP. An overview of micro-and nanoemulsions as vehicles for essential oils: formulation, preparation and stability. Nanomaterials 2020;10:2-24.

38. Lallemand F, Daull P, Simon B, Ronald B, Garrigue JS. Successfully improving ocular drug delivery using the cationic nanoemulsion, novasorb. J Drug Delivery 2012;1-16. Doi:10.1155/2012/604204

39. Baranowski P, Karolewicz B, Gajda M, Pluta J. Ophthalmic drug dosage forms: characterization and research methods. Sci World J 2014:2014:1-14.

40. Ammar HO, Salama HA, Ghorab M, Mahmoud AA. Nanoemulsion as a potential ophthalmic delivery system for dorzolamide hydrochloride. AAPS PharmSciTech 2009;10:808-19.

41. Morsi NM, Mohamed MI, Refai HM, Sorogy EL. Nanoemulsion as a novel ophthalmic delivery system for acetazolamide. Int J Pharm Pharm Sci 2014;6:227-36.

42. Zainol S, Basri M, Basri HB. Formulation optimization of a palm-based nanoemulsion system containing levodopa. Int J Mol Sci 2012;13:13049-64.

43. Koteswari P, Rama KS, Prabhakar RV, Lakshmi NM. Formulation and preparation of felodipine nanoemulsions. Asian J Pharm Clin Res 2011;4:116-7.

44. Yadav P, Vaibhav R, Verma A. Application of Box-Behnken design and desirability function in the development and optimization of self-nano emulsifying drug delivery system for enhanced dissolution of ezetimibe. Future J Pharm Sci 2020;6:2-20.

45. Sayed S, Ibrahim E. Tailored nanostructured platforms for boosting transcorneal permeation: box-behnken statistical optimization, comprehensive in vitro, ex vivo and in vivo characterization. Int J Nanomed 2017;12:7947-62.

46. Daull P, Lallemand F, Garrigue JS. Benefits of cetalkonium chloride cationic oil-in-water nanoemulsions for topical ophthalmic drug delivery. J Pharm Pharmacol 2014;66:531-41.

47. Ban J, Zhang Y, Huang X, Deng GH, Hou DZ, Chen YZ, et al. Corneal permeation properties of a charged lipid nanoparticle carrier containing dexamethasone. Int J Nanomed 2017;12:1329-39. 